\title{
SUBVERSÃO DO SIGNO HEGEMÔNICO DA REPRESENTAÇÃO SINDICIAL: ANÁLISE-CRÍTICA DAS DESIGUALDADES DENTRO DOS SINDICATOS À LUZ DO SEGUNDO PRINCÍPIO DA JUSTIÇA DE JOHN RAWLS

\author{
ANALYSIS OF INEQUALITIES WITHIN UNIONS IN THE \\ LIGHT OF JOHN RAWLS 'SECOND PRINCIPLE OF JUSTICE
}

RAINER BOMFIM ${ }^{1}$

MARINA SOUZA LIMA ROCHA ${ }^{2}$

\section{RESUMO}

John Rawls, em sua obra "Uma Teoria da Justiça", realiza explanações sobre o que considera ser a Teoria da Justiça através da análise de dois princípios: o primeiro, que trata sobre liberdades básicas iguais para todos; o segundo, que trata sobre igualdade e equilíbrio nas desigualdades sociais e econômicas e a sua vinculação com a acessibilidade a cargos e posições de lideranças a todos. 0 autor afirma que tais princípios devem ser adotados por entes coletivos que chama de Instituições Sociais, que, por sua vez, formam a estrutura básica da sociedade. No âmbito do Direito do Trabalho Coletivo, identifica-se que os sindicatos se amoldam ao conceito de instituições sociais descrito por Rawls, de maneira que se torna conveniente a análise da aplicabilidade dos princípios da justiça em tais entes. Pode-se tomar como base a análise da aplicabilidade do segundo princípio da justiça, uma vez que os sindicatos se mostram, historicamente, como instituições que priorizam em sua estrutura interna a voz dos homens brancos, heterossexuais e cisgêneros. Ao realizar uma análise crítica da estrutura dos sindicatos, sugere-se que a aplicação do segundo princípio da justiça, como equilibrador de desigualdades sociais, econômicas e de oportunidade de acesso a cargo e posições, auxiliaria na pluralização do ambiente interno de tais entes, de maneira que as suas próprias demandas e bandeiras de luta naturalmente seriam alteradas de modo a abarcar trabalhadores/as pertencentes às mais variadas classes sociais, econômicas e culturais, proporcionando um ambiente mais justo, segundo a visão liberal igualitária de justiça de Rawls.

PALAVRAS-CHAVE: Direito Coletivo do Trabalho. Teoria da Justiça. John Rawls. Sindicato.

\footnotetext{
1 Mestrando em Direito pela Universidade Federal de Ouro Preto (UFOP). Especialista em Direito da Previdência Social pela FAVENI. E-mail: rainerbomfim@outlook.com.

2 Mestranda em Direito pela UFOP. Bolsista UFOP. E-mail: marinarocha.direito@gmail.com.
} 


\section{ABSTRACT}

John Rawls, in his work "A Theory of Justice", explains what to consider the Theory of Justice through the analysis of two principles: the first, which deals with equal basic freedoms for all; the second, which deals with balance and balance in social and economic economies and their connection with accessibility to loads and leadership positions in all. The author states that such principles must be adopted by collective entities that they call Social Institutions, which, in turn, form a basic structure of society. Within the scope of Collective Labor Law, it is identified that the indicators conform to the concept of social institutions described by Rawls, so that it is convenient to analyze the application of the principles of justice in such entities. The applicability analysis of the second principle of justice can be taken as a basis, since indicators are historically more common as institutions that prioritize the voice of white, heterosexual and cisgender men in their internal structure. When performing a critical analysis of the structure of the indicators, we suggest that you apply the second principle of justice, such as the balance of social inequalities, the economy and the opportunity to access loads and positions, assist in the pluralization of the internal environment of such entries, in a way that its demands demand and fight flags normally altered in order to include workers tend to occur in more social, economic and cultural classes, to use a fairer environment, according to Rawls' liberal egalitarian vision of justice.

KEYWORDS: Collective Labor Law. Theory of Justice. John Rawls. Syndicate.

\section{INTRODUÇÃO}

Sob a vertente metodológica jurídico-crítica (GUSTIN, DIAS, 2013, p. 23), objetiva-se analisar a desigualdade dentro dos sindicatos com o enfoque na teoria política de John Rawls, especialmente o segundo princípio de justiça elaborado pelo autor no livro "Uma teoria da justiça" (2008). 0 trabalho justifica-se pela centralidade da atuação sindical na luta do Direito Coletivo do Trabalho que se concentra num signo masculino, branco, cisgênero, sendo centrado num sujeito tipicamente marcado como moderno. Assim, a eleição e a análise dentro do espectro da filosofia política é uma escolha de, aos poucos, ocupar espaços estratégicos que também são majoritariamente masculinos, brancos e elitizados por um paradigma de conhecimento hegemônico no norte global (BALLESTRIN, 2003; EISENSTEIN, 2014).

Dessa forma, a questão-problema a ser respondida é se com a aplicação prática do segundo princípio (igualdade), elaborado por John Rawls, o sindicato se tornaria uma instituição mais democrática e atenta às demandas da sociedade contemporânea? Frente a isso, a hipótese deste trabalho é que caso se respeite o referido princípio, nos moldes e pressupostos apresentado pelo filósofo, se teria uma estrutura mais aberta à pluralidade dos sujeitos e mais igualitária àqueles/as trabalhadores/as da modernidade.

Contextualizando, tem-se que um dos principais entes de representação coletiva do país (se não o principal) é o sindicato, pois se trata de órgão estruturado, com proteção constitucional, para dar voz à classe trabalhadora em sua injusta relação estabelecida com os empregadores. Portanto, perceber o porquê de sua existência com proteção normativa é tentar estabelecer diálogos, conflitos e regras, através da criação de normas coletivas (Acordos Coletivos de Trabalho e Convenções Coletivas de Trabalho), que garantam aos/às trabalhadores/as o mínimo de direitos necessários para que com aquela relação de emprego se estabeleça uma vida digna e justa, conforme os ditames da Constituição Federativa da República do Brasil de 1988 (CFRB/88) e da Organização Internacional do Trabalho (OIT). 
Dessa maneira, o alcance do que é intitulado como "vida digna e justa" seria através da efetivação dos princípios fundamentais da CFRB/88, sendo importante que para este alcance os sindicatos ajam de maneira justa e inclusiva em suas negociações. Ocorre que, dentro de sua própria estrutura interna, os sindicatos não costumam ser justos no que tange à distribuição de cargos e posições, reproduzindo as práticas discriminatórias sofridas pela população marginalizada da sociedade e contribuindo para a perpetuação de desigualdades econômicas e sociais de membros da heterogênea classe trabalhadora.

Os sindicatos, em sua grande maioria, se mostram como um retrato do que ocorre nas empresas: homens brancos e cis são priorizados em face das demais classes e gêneros. Mulheres ${ }^{3},{ }^{4}$ por exemplo, ainda não alcançaram o patamar de liderança necessário à garantia de sua justa representação nestes órgãos. 0 que faz necessário um constante trabalho de conscientização da classe trabalhadora acerca da importância da valorização da figura feminina no ambiente de trabalho.

Assim, torna-se impetuoso repensar a maneira com que os sindicatos, em suas próprias dinâmicas internas, realizam a distribuição de cargos e posições, sendo a aplicação da "Teoria da Justiça" de John Rawls para a realização de uma reflexão acerca da injustiça que paira sob essas instituições.

O trabalho é desenvolvido com uma apresentação dos sindicatos enquanto instituições sociais, em seguida se apresenta o segundo princípio da teoria da justiça de Ralws e se conclui o texto com a construção à necessidade de se reformular as estruturas internas do sindicato, em busca de maior justiça e igualdade.

\section{O SINDICATO COMO INSTITUIÇÃO SOCIAL}

As instituições sociais são fundamentais para o bom funcionamento da sociedade e, compreendê-las como entes coletivos e partes integrantes de nossa complexa estrutura normativa, é tarefa que demanda certo aprofundamento e atenção (RAWLS, 2008). John Rawls (2008, p. 58) afirma em seu livro "Uma teoria da justiça" que instituições sociais são um sistema público de regras que definem cargos e posições com seus direitos e deveres, poderes e imunidades.

Pode-se dizer, portanto, que cada instituição social possui um conjunto normativo que rege o comportamento de seus indivíduos, seja pelo caráter coercitivo de suas normas, ou

3 Há comprovação estatística quanto ao fato de haver flagrante e persistente desigualdade de gênero no mercado de trabalho que impede a mulher de usufruir das mesmas condições, salários e oportunidades que o homem nesta esfera. Segundo dados colhidos pelo IBGE (Instituto Brasileiro de Geografia e Estatística), as mulheres, em 2016, possuíam rendimento médio mensal de R\$1.764, enquanto o dos homens equivalia a R\$2.306. Isto se dá, boa parte, em função dos homens ocuparem maioria dos cargos gerenciais (públicos ou privados) do país: segundo dados do mesmo instituto, $60,9 \%$ destes cargos eram ocupados por homens e somente $39,1 \%$ por mulheres, mesmo estas últimas tendo, em média, nível de formação superior ao dos homens (também segundo dados do IBGE). Ademais, a invisibilidade e vulnerabilidade nos ambientes de trabalho se justifica pelo fato de que as mulheres têm, em sua maioria, que cumprir jornada dupla de trabalho, posto que continuam sendo as grandes responsáveis também pelos afazeres domésticos, segundo o IBGE (dedicaram, em 2016, 73\% a mais de horas do que os homens em afazeres domésticos semanais) (BRASIL, IBGE, 2018).

4 Considera-se, no âmbito desta investigação, o termo mulheres no sentido heterogêneo, compreendido o universo plural e ampliado do qual participam mulheres, mulheres LGBTI+, mulheres negras e outras classificações. Considera-se, também, no mesmo sentido, a heterogeneidade das trabalhadoras mulheres participantes do universo plural e disperso dos trabaIhadores em geral. 
pela sua aceitação e reconhecimento como estruturas coletivas normatizadas (RAWLS, 2008).

Para Rawls (2008), o alcance do que considera uma "Teoria da Justiça" depende de instituições sociais equilibradas, efetivas e justas, que formam, por sua vez, uma estrutura social básica fundamental para a sociedade. Ademais afirma que a justiça social depende da cooperação dessas instituições para efetivação de seus princípios:

O primeiro objeto dos princípios da justiça social é a estrutura básica da sociedade, a ordenação das principais instituições sociais em um esquema de cooperação. Vimos que esses princípios devem orientar a atribuição de direitos e deveres nessas instituições e determinar a distribuição adequada aos benefícios e encargos da vida social. Os princípios da justiça para instituições não devem ser confundidos com os princípios que se aplicam aos indivíduos e às suas ações em circunstâncias particulares. (RAWLS, 2008, pp. 57-58).

Nesse sentido, os sindicatos se amoldam ao conceito de instituições sociais, uma vez que representam uma coletividade de trabalhadores e trabalhadoras e, em sua dinâmica interna delega cargos, regras, direitos e deveres.

A classe trabalhadora representa, historicamente, um povo (super)explorado, que foi alijado dos meios de produção pelos detentores de capital, restando-a vender sua força de trabalho para sobreviver (MARX, 2014). Por isso o/a trabalhador/a representa a parte hipossuficiente da relação de trabalho e, para diminuir a desigual relação entre capital e trabalho, se organiza com os/as demais de sua classe para formarem um sujeito de luta coletivo que estabeleça uma relação de maior simetria para enfrentar e negociar com o/a empregador/a.

Diante disso, sabe-se que os sindicatos podem ser instituições injustas e excludentes, contudo, é importante que existam tais instituições, para que mesmo as tentativas falhas sejam transformadas em exemplos da eventual aplicação de uma teoria da justiça (RAWLS, 2008).

\section{SINDICATOS: INSTITUIÇÓES SOCIAIS JUSTAS?}

Para que se possa falar em sindicatos justos, é fundamental que o seu comando seja imparcial e efetivo, de tal forma que se entende aqui por imparcialidade que os sindicatos devem se abster de juízos de valor em sua administração e ações junto ao seu público. Um exemplo dessa imparcialidade seria o de que seus diretores ou dirigentes não devem deixar de agregar em sua estrutura de funcionamento pessoas de determinado gênero ou raça por razões estritamente pessoais e subjetivas. Outro exemplo seria o de não deixar o poder do capital influenciar nas negociações coletivas que estabelecem com os/as empregadores/as (é de certa forma uma utopia dizer isso, pois, numa interpretação marxista, o capital é quem comanda essa relação "empregador/a x trabalhador/a". Mas, ao mesmo tempo, seria também uma utopia pensar em uma teoria da justiça para aplicação no âmbito sindical em um sistema capitalista, sendo que ambas as partes estão em reconhecida desigualdade material?). 
Igualmente, entende-se que o próprio exercício de se pensar uma forma ideal, justa e imparcial de funcionamento dos sindicatos pode ser um exercício utópico, porém, não deixa de ser necessário, pois, segundo Rainer Forst ${ }^{5}$, a justiça plena ${ }^{6}$, na visão empregada pelo autor, pode ser, de fato, inalcançável, porém, é inevitável a sua constante busca pelos cidadãos (FORST, 2018, p. 243).

Os sindicatos, por mais que não consigam ser totalmente justos em suas atuações, conseguem ao menos amenizar a disparidade causada pela relação exploradora entre empregadores e trabalhadores(as), o que fortalece a liberdade de luta da classe trabalhadora.

O autor, aprofundando ainda mais no tema, bem como introduzindo o conceito de justiça formal, afirma:

Imaginemos ainda que essa concepção da justiça tem uma ampla aceitação na sociedade e que as instituições são imparcial e consistentemente administradas por juízes e outras autoridades. Ou seja, casos similares são tratados de modo similar, as similaridades e diferenças sendo aquelas identificadas pelas normas existentes. A regra correta definida pelas instituições é regularmente observada e adequadamente interpretada pelas autoridades. $\mathrm{A}$ essa administração imparcial e consistente das leis e instituições, independentemente de quais sejam seus princípios fundamentais, podemos chamar de justiça formal. Se pensamos que a justiça sempre expressa algum tipo de igualdade, então a justiça formal exige que em sua administração as leis e instituições se devam aplicar igualmente (ou seja, do mesmo jeito) àqueles que pertencem às categorias definidas por elas. [...] A justiça formal é a adesão ao princípio, ou, como disseram alguns, a obediência ao sistema (RAWLS, 2008, p. 61-62).

De tal maneira que se pode chamar de justiça formal o fato dos sujeitos da relação trabalhista (trabalhadores/as e empregadores/as) respeitarem as regras e os princípios estabelecidos pelas instituições que os comandam (ex: Justiça do Trabalho, legislação, súmulas, orientações jurisprudenciais e sindicatos). Dessa forma, se há o reconhecimento geral de que uma norma coletiva, uma lei ou um costume deve ser respeitado, independente se são, de fato, justas ou não, existe então a figura da justiça formal ou apenas numa concepções formalísticas.

Segundo John Rawls (2008), mesmo que as leis e instituições (neste caso, os sindicatos) sejam injustas (em diferentes níveis), é menos danoso que haja o respeito às suas determinações, do que se estabelecer um ambiente desinstitucionalizante, sem regras e sem leis. Afirma o autor que, mesmo as instituições injustas (como são a maioria dos sindicatos e suas negociações coletivas) fazem mais justiça do que a ausência de normatividade e de uma instituição que represente a classe trabalhadora. Frise-se que este é o posicionamento de Rawls (2008), não sendo necessariamente o entendimento correto ou hegemônico.Um ambiente que possui normas injustas abre margem para que ocorram diversos tipos de discriminação, como o machismo, racismo e o autoritarismo, por exemplo. Frente a isso, mostra-se necessário ter o entendimento que não são todas as injustiças que são justificáveis sob o pretexto de que a ausência de normas seria mais danosa (RAWLS, 2008).

5 Para mais informações, consultar a obra de 2018 de Rainer Forst: Justificação e Crítica. Perspectivas de uma teoria crítica da política.

6 Questiona-se quais são essas condições de justiça plena num contexto capitalista de exploração da mão de obra dos trabalhadores/as, mas mantém pela tradição da filosofia política adotada. 
Dessa forma, um começo para o alcance de uma teoria da justiça é que se estabeleça um padrão mínimo aceitável de reconhecimento às instituições e suas normas. No caso, o próprio fato dos sindicatos existirem e possuírem determinado poder de negociação já é um primeiro passo para a aplicação dos princípios explicitados por Rawls, necessários para a efetivação da teoria da justiça.

\section{OS PRINCÍPIOS DA JUSTIÇA DE JOHN RAWLS}

Os sindicatos são instituições sociais que possuem poderes de negociação coletiva visando estabelecer um mínimo normativo necessário à existência de uma justiça formal. Diante disso, passa-se à análise dos "princípios da justiça" que, segundo Rawls, são necessários à efetivação de uma estrutura plenamente justa.Segundo o Autor, os dois princípios são os seguintes:

Primeiro: cada pessoa deve ter um direito igual ao mais abrangente sistema de liberdades básicas iguais que seja compatível com um sistema semeIhante de liberdades para as outras.

Segundo: as desigualdades sociais e econômicas devem ser ordenadas de tal modo que sejam ao mesmo tempo (a) consideradas como vantajosas para todos dentro dos limites do razoável, e (b) vinculadas a posições e cargos acessíveis a todos (RAWLS, 2008, p. 64).

Afirma que o primeiro princípio antecede ao segundo, de maneira que deve ser assegurado a todos liberdades básicas iguais (liberdade política para votar, liberdade de expressão para manifestar e falar, liberdade de consciência, etc ${ }^{7}$ ). Apenas depois, deve-se assegurar que a distribuição de riqueza e oportunidades deve ser vantajosa a todos, mesmo que não seja igual. De acordo com o segundo princípio, todos(as) devem ter as mesmas oportunidades e os cargos de autoridade e responsabilidade a todos(as) devem ser acessíveis.

Para o que interessa ao ponto de vista do Direito do Trabalho Coletivo, pode-se afirmar que, em um sistema capitalista neoliberal ${ }^{8}$, torna-se tarefa hercúlea enxergar um horizonte, mesmo que longínquo, que assegure uma justa distribuição de riquezas. Ademais, há baixo vislumbre de possiblidade de que todos/as tenham acesso aos cargos de autoridade e res-

7 Para que se entenda a importância do conceito de "liberdades básicas" para Rawls, transcreve-se lição de Denilson Luis Werle, que ao explicar do que se tratam, afirma que são a condição básica para o adequado desenvolvimento e exercício pleno das capacidades morais do ser humano. Vejamos: "Rawls continuará a manter a tese da prioridade da liberdade no sentido de que uma liberdade só pode ser limitada ou negada em nome de uma outra ou de outras liberdades fundamentais, e nunca por considerações de bem estar geral ou por valores perfeccionistas. Sendo que as liberdades fundamentais podem ser limitadas quando entram em choque entre si, nenhuma delas pode ser considerada absoluta. Para justificar a prioridade das liberdades básicas Rawls esclarece qual o conceito de pessoa que está na base do liberalismo político. Além de serem vistas como cidadãos livres e iguais, as pessoas são tidas como cidadãos que possuem duas faculdades (ou capacidades) morais: a de terem um senso de justiça e a de formar, buscar e revisar uma concepção racional do bem. A lista de liberdades básicas sugerida por Rawls representa as condições sociais fundamentais para o desenvolvimento adequado e exercício pleno dessas duas capacidades da pessoa durante a vida inteira, fundamentais para o desenvolvimento de um senso de independência pessoal e de auto-respeito [...] O que justifica o conceito de pessoa adotado por Rawls é o próprio propósito da justiça como equidade: "o objetivo é formular uma concepção de justiça política e social afim às convicções e tradições mais profundamente arraigadas de um Estado democrático moderno. O propósito de fazer isso é verificar se podemos resolver o impasse de nossa história política recente, qual seja, de que não há concordância sobre a forma pela qual as instituições básicas devem ser organizadas para se harmonizarem com a liberdade e igualdade dos cidadãos enquanto pessoas" (WERLE, 2011, p. 190-191).

8 "O neoliberalismo pode ser definido como o conjunto de discursos, práticas e dispositivos que determinam um novo modo de governo dos homens segundo o princípio universal da concorrência" (DARDOT; LAVAL, 2019, p. 15). 
ponsabilidade, uma vez que estes, em ambientes sindicais em geral, pertencem quase que exclusivamente a homens brancos e cis.

Sintetizando o entendimento sobre os dois princípios, portanto, o fato de Rawls afirmar que ambos se aplicam às instituições sociais, nos faz pressupor que são aplicáveis, por consequência, aos sindicatos.

\section{A APLICAÇÁOO DO SEGUNDO PRINCÍPIO DA JUSTIÇA AO SINDICATO}

Se os/as trabalhadores/as possuem todas as suas liberdades preservadas, parte-se para a efetivação do segundo princípio, que determina uma distribuição de riquezas que seja benéfica a todos. Contudo, seria inocência afirmar que os/as trabalhadores/as, mesmo com a intervenção das instituições sociais (sindicatos), possuem preservadas as suas liberdades básicas. Para exemplificar, basta apontar que, mesmo com a previsão formal de que todos/ as possuem liberdade para exercer o direito de greve quando, onde e como acharem conveniente (art. 9, $\mathrm{CFRB} / 88^{9}$ ), vê-se o tempo todo o judiciário declarando ilegalidades em legítimos movimentos paredistas, ao revés do disposto na CFRB/88, utilizando como argumento uma legislação infraconstitucional (Lei de Greves $-n^{0} 7.783 / 89^{10}$ ) que tem o único papel de limitar um exercício que, por determinação da nossa constituição, deveria ser pleno. Nesse sentido explica Rafael Borges Bias:

Há um conflito entre o texto restritivo da Lei 7.783/89 e o artigo $9^{\circ}$ da Constituição, que estabelece uma concepção ampla do direito de greve, transferindo aos trabalhadores a responsabilidade para decidir o momento e a forma de deflagração, bem como as reivindicações que buscam conquistar. Foi delegada à lei ordinária apenas a definição dos serviços e atividades essenciais, além do tratamento das necessidades inadiáveis da comunidade, nos exatos termos do parágrafo $1^{\circ}$ do artigo $9^{\circ}$. Entretanto, a Lei $7.783 / 89$ é um compêndio de limitações ao exercício do direito de greve, ferindo a constituição, que não possui nenhuma expressão sujeitando forma, finalidade ou exercício da greve à norma específica. 0 conceito de greve é constitucionalmente definitivo, não permitindo restrições. (BIAS, 2014, p. 7).

Márcio Túlio Viana defende que a existência dessa lei infraconstitucional não deveria ser uma limitação ao pleno exercício das greves, vez que ela deveria ser lida de forma crítica, sem perder de vista a base constitucional (VIANA, 1996, p. 302). Ocorre que, infelizmente, o que se vê na prática é uma real limitação do exercício pleno do direito de greve.

9 Art. $9^{\circ}$ É assegurado o direito de greve, competindo aos trabalhadores decidir sobre a oportunidade de exercê-lo e sobre os interesses que devam por meio dele defender. (BRASIL, 1988).

10 Alguns autores afirmam que tal lei é inconstitucional. Dentre eles, destaca-se a lição de Baboin: “Desta forma, a Lei 7.783/89, ao fixar restrições ao direito garantido no artigo $9^{\circ}$ da Carta Magna, o faz de forma inconstitucional. Não pode mera lei ordinária, cuja aprovação exige apenas a maioria simples de votos, impossibilitar o exercício de direito constitucional, direito este que inclusive reveste-se de caráter fundamental em nosso ordenamento. Como aponta José Afonso da Silva, 'a melhor regulamentação do direito de greve é a que não existe. Lei que venha a existir não deverá ir no sentido de sua limitação, mas de sua proteção e garantia"'. (BABOIN, 2013, p. 33). Para mais informações sobre o tema, ver: "Greves Atípicas: um novo olhar sobre os movimentos de resistência da classe trabalhadora" de Marina Souza Lima Rocha. 
Sendo assim, vê-se que, ao menos no Brasil, as instituições sociais (seja o Judiciário, sejam os sindicatos) não conseguem garantir nem a observância total do primeiro princípio de justiça de Rawls, de maneira que o alcance do segundo se torna igualmente limitado.

O autor, após longa explicação e desconstrução dos conceitos dos diversos princípios e subprincípios que acredita fazerem parte deste sistema, chega à teoria que acha adequada para a construção de um ideal de justiça e que, consequentemente, se mostra também adequada à idealização dos sindicatos, objeto deste estudo (RAWLS, 2008). Trata-se da "Igualdade Democrática" e o "Princípio da Diferença" (RAWLS, 2008).

Afirma Ralws, acerca destes institutos, especificamente sobre o princípio da diferença, que se trata de um esquema em que a expectativas de todas as pessoas pertencentes à sociedade aumentam, independentemente de sua classe social, na medida em que a expectativa de alguma delas, isoladamente, aumenta. Desta maneira, a desigualdade pode se manter entre elas, porém, a expectativa de todas elas melhora quando alguma delas alcança patamares superiores. Veja-se:

Simplesmente maximizamos as expectativas da posição menos favorecida, obedecendo as limitações exigidas. Contanto que isso traga benefícios para todos, como supus até agora, os ganhos estimados, em relação a situação de igualdade hipotética são irrelevantes, quando não impossíveis de determinar. Pode haver, entretanto, um outro sentido em que todos se beneficiam quando o princípio da diferença é satisfeito, ao menos se fizermos algumas suposições. Suponhamos que as desigualdades nas expectativas estão ligadas em cadeia: ou seja, se uma vantagem tem o efeito de elevar as expectativas da posição mais baixa, ela também eleva as expectativas de todas as camadas intermediárias (RAWLS, 2008, p. 85).

Por fim, aponta Rawls que o Princípio da Diferença dá peso às considerações descritas por outro princípio: o princípio da reparação (RAWLS, 2008, p. 107). Este último princípio, segundo o autor, prevê que: "desigualdades imerecidas exigem reparação; e como desigualdades de nascimento e de dotes naturais são imerecidas, elas devem ser de alguma forma compensadas" (RALWS, 2008, p. 107). Esse tipo de desigualdade imerecida se encontra amplamente presente dentro dos sindicatos, cujos cargos de liderança são ocupados, em sua maioria, por homens brancos, justamente por serem constituídos dessas características naturais supervalorizadas pela modernidade (BALLESTRIN, 2013.).

Tal modelo de sindicato representa o espelho da fábrica taylorista-fordista, composta, em sua maioria, por homens brancos, "operários manejando equipamentos industriais e vestidos com macacões" (RODRIGUES, 2019, p. 4). Dessa forma, tipificar a classe trabalhadora de forma homogênea, como se ela se encaixasse apenas no molde branco, industrial, masculino e assalariado é perpetuar um espaço sindical excludente, configurado por uma homogeneidade incolor e masculina (PEREIRA, 2017). É ignorar uma pluralidade de experiências e lutas daqueles/as que não se encaixam nesse padrão moderno (PEREIRA, 2017).

Fica nítido, portanto, que, adotando-se o ponto de vista da igualdade democrática, a junção entre o Princípio da Diferença e o Princípio da Reparação se mostra um bom caminho para a pavimentação das instituições sociais rumo à uma efetiva teoria da justiça.

Igualmente, se os sindicatos conseguissem, através da reformulação de seus estatutos e dinâmica interna, fazer com que a atuação dos sindicalistas fosse mais diversificada e plural, como a classe trabalhadora, isso se refletiria em benefícios para os/as trabalhadores/ 
as (Princípio da Diferença).Assim, o ponto de partida dos desfavorecidos/as, ou daqueles/ as que não possuem oportunidades em função da sua classe social, gênero ou raça, será o tanto igualitário quanto possível no seu interior, o que reverberará também no mercado de trabalho e, consequentemente, na sociedade como um todo (Princípio da Reparação). Dessa forma, constituir-se-ia realmente instituições sociais coletivas que não só promovem a Justiça Social, como a efetivam por meio de suas ações.

A maneira, contudo, como tais instituições sociais devem aplicar conjuntamente os princípios da diferença e da reparação, já se trata de outra reflexão, que, tendo em vista sua enorme complexidade e dificuldade de superação, deve ser objeto de novo estudo, desta vez empírico.

\section{REORGANIZAÇÃO DA ESTRUTURA SINDICAL}

O problema que se observa é a estrutura injusta, hierarquizada, preconceituosa e patriarcal que se encontra no interior dos sindicatos. Como estes, que são os sujeitos coletivos representantes da heterogênea classe trabalhadora, podem lutar por justiça e maiores direitos trabalhistas na relação capital/trabalho, se eles mesmo são instituições injustas, excludentes e desiguais?

Dessa forma, os sindicatos brasileiros são compostos, em sua grande maioria, por homens brancos e cisgêneros, principalmente quando se avalia os cargos de liderança (dirigentes sindicais). Se mulheres, negros, pessoas transexuais ${ }^{11}$ e outros sujeitos marginalizados não participam (ou participam minimamente) da composição dos sindicatos, então suas vozes não são ouvidas e sequer lembradas. Assim, esses sujeitos e sujeitas são excluídos não só do mercado de trabalho, mas da própria luta de classes.

A ausência ou baixa diversidade social, racial e de gênero nos sindicatos pode ser diagnosticada como uma reprodução da desigualdade estrutural da sociedade, o que acaba aprofundando e gerando cada vez mais desigualdades no mercado de trabalho e na sociedade como um todo, se configurando em um ciclo vicioso histórico de exclusão permanente de determinados sujeitos (RODRIGUES, 2018). Segundo Adriana L. Saraiva Lamounier Rodrigues "um sindicato que discrimina, que ignora as minorias, que reproduz discursos machistas não representará seus trabalhadores. A democracia tem que começar dentro das entidades sindicais para quem sabe um dia alcançar também a esfera empresarial (RODRIGUES, 2018, p. 92). É necessário quebrar esse ciclo. A desigualdade não se inicia nos sindicatos, mas é apropriada por esses entes coletivos. Dessa forma, combater e romper com ela dentro dos sindicatos afetará de forma direta os níveis de desigualdade (e, consequentemente, de igualdade) no mercado de trabalho e na sociedade.

11 Se tais características já são marginalizadas separadamente, imagine, então, uma mulher negra, transexual e de classe social baixa? Por isso, é fundamental considerar a interseccionalidade. Segundo Crenshaw, a ideia de intersccionalidade "refuta o enclausuramento e a hierarquização dos grandes eixos da diferenciação social que são as categorias de sexo/ gênero, classe, raça, etnicidade, idade, deficiência e orientação sexual. 0 enfoque interseccional vai além do simples reconhecimento da multiplicidade dos sistemas de opressão que opera a partir dessas categorias e postula sua interação na produção e na reprodução das desigualdades sociais" (CRENSHAW, 2002). 
Por conseguinte as questões de raça e gênero, em especial, se mostram fundamentais para a construção de uma maior representatividade e força política do sindicato. Isso porque a presença de questões de movimentos sociais na pauta dos sindicatos é essencial para se considerar "o caráter plural da classe trabalhadora contemporânea, no seio da qual as clivagens de gênero e raça costumam gerar situações de precariedade ainda maiores para aqueles que não se incluem na mão-de-obra masculina e branca" (DA SILVA, 2010, p. 122).

Em relação aos negros e negras há um problema estrutural da sociedade, que é comprovado pela existência de uma carga extra de problemas sobre eles/as, decorrente de sua condição racial (SILVA, 2008). Jair Batista da Silva, em seu texto intitulado" Racismo e Sindicalismo - reconhecimento, redistribuição e ação política das centrais sindicais acerca do racismo no Brasil (1983-2002)" traz parte da resolução do 5 Congresso Nacional da CUT para demonstrar a realidade vivenciada pelos/as negros/as e a apatia dos sindicatos brasileiros:

0 reconhecimento de que as desigualdades raciais constituem um problema estrutural da sociedade brasileira implica reconhecer o papel fundamental do movimento sindical no combate ao racismo. Noutras palavras, implica reconhecer que, ao não enfrentar a questão racial, o movimento sindical legitima e contribui para a reprodução das desigualdades raciais, frustrando uma espécie de acordo tácito entre o Estado opressor e autoritário e o sindicalismo em torno da marginalização do povo negro. 0 acordo de que falamos explica o fato de que os dados publicados pelo DIEESE não são sequer lidos pela maioria dos dirigentes, nem considerados na ação sindical. Com efeito, diante do debate sobre a questão racial, os dirigentes se limitam a manifestações solenes de solidariedade que nunca ultrapassam o discurso, isso na melhor das hipóteses. Mas há casos mais esquisitos, em que companheiros sem qualquer informação a não ser aquela fornecida pela ideologia dominante deitam falação sobre as - vantagens e os benefícios do racismo brasileiro se comparado ao sul-africano ou ao norteamericano. Tomados em conjunto, tais comportamentos configuram o desserviço prestado pelo sindicalismo à luta contra o racismo, compreendida como parte integrante da luta pela democratização da sociedade brasileira. A responsabilidade do sindicalismo no combate ao racismo não se deve, diga-se de passagem, a questões de natureza humanitária, mas ao fato de que metade dos trabalhadores são negros e, portanto, é dever do sindicato incorporar os interesses desse segmento [(Resoluções do 5 Congresso Nacional da CUT). CUT, 1994, p. 132 - Grifo JBS] (SILVA, 2008, p. 103-104).

Em relação às mulheres, uma pesquisa realizada pela Dieese em 2017 sobre o número de dirigentes sindicais por grupo e sexo demonstrou que, dos 139.567 dirigentes sindicais de sindicatos trabalhistas do Brasil, 99.738 são homens e apenas 39.829 são mulheres (FONTE). 0 resultado da pesquisa demonstra uma grande desigualdade na estrutura interna dos sindicatos, que privilegia homens em cargos de direção e que, "mesmo quando as mulheres conseguem fazer parte das lideranças, elas dificilmente têm voz" (BERTOLIN; KAMADA, 2012, p. 47), pois são minoria e dificilmente encontram solidariedade em uma estrutura arcaica e engessada.

Em relação à questão de gênero, Sara Deolinda Cardoso Pimenta (2012) ressalta que a tradição masculina do sindicalismo gera a invisibilidade das mulheres no mundo do trabalho e se reproduz historicamente no discurso sociológico ao tratar a classe social sem se referir ao sexo dos atores sociais. Mesmo com o avanço dos movimentos feministas, para a autora, os sindicatos permanecem sob a ótica masculina e as mulheres são objeto de uma 
sociologia específica, "como se o lugar da produção de onde se tratava a classe social fosse dissociado das relações sociais" (PIMENTA, 2012).

Precisa existir uma compatibilidade entre o que pregam os sindicatos e como eles se organizam internamente. 0 discurso sindical que defende a democracia, a justiça e a superação das desigualdades, muitas vezes não encontra respaldo nas relações práticas cotidianas, assim mascarando as relações de opressão e discriminação (PIMENTA, 2012). Em relação a presença das mulheres nessas instituições sociais, Junéia Batista, secretária da Mulher Trabalhadora da Central Única dos Trabalhadores (CUT), em entrevista destacou: "Mesmo o número de mulheres no mundo do trabalho ter (sic) aumentado, a presença delas no sindicato ainda não reflete essa proporção, em especial quando verificamos os cargos de poder nas organizações sindicais" (CONFEDERAÇÃO, 2016).

A classe trabalhadora não pode ser tida mais somente como aquela constituída "pelo operariado, empregado, sindicalizado no âmbito industrial de uma empresa taylorista-fordista verticalizada, concentrada em um único espaço de produção no território nacional" (FLEURY; NICOLI, 2018, p. 15-16). A classe trabalhadora é plural, colorida, heterogênea, composta pelas mais diversas clivagens (PEREIRA, 2017). Por isso, a participação de sujeitos invisibilizados (na sociedade contemporâneas e nas relações trabalhistas) na estrutura interna dos sindicatos pode romper com uma estrutura homogênea, branca e patriarcal da luta de classes herdado da modernidade, que busca apagar as complexas diversidades do tecido social (EISENSTEIN, 2014, p. 2)Nesse sentido, para a ressignificação da categoria classe social -e, consequentemente, para a recuperação da eficácia das lutas coletivas no capitalismo contemporâneo ${ }^{12}$ - deve-se superar a análise herdada do paradigma racional-moderno que a concebe como algo homogêneo, e, portanto, incolor, universalista como em branco, cisgênero e masculino: o trabalho vem em cores, sexos, gêneros e é formulado mediante expressões de poder que atravessam aqueles sujeitos dentro das suas diversas relações sociais (PEREIRA, 2017).

Para que os sindicatos se configurem como instituições sociais justas, que proporcionam uma estabilidade da sociedade bem organizada, eles precisam amparar a luta de toda classe trabalhadora, para que tenham condições dignas de vida e trabalho, bem como direito de acesso aos cargos internos da estrutura sindical, com participação efetiva na luta de classes. A desigualdade que vemos dentro dos sindicatos, dominados por homens cisgêneros brancos, é uma desigualdade prejudicial, que lesa a representação de sujeitos que já são marginalizados na sociedade e no mercado de trabalho.

Por serem desigualdades injustas e prejudiciais (que não se encaixam no Princípio da Diferença de Rawls, explicado anteriormente) àqueles que já se encontram em situações de maior precariedade e exploração, devem ser transformadas para que cessem as injustiças dentro dos sindicatos, que devem ser instituições sociais justas.

O segundo princípio da justiça permite desigualdades, mas apenas se elas trouxerem benefícios a todos, o que não ocorre no problema aqui tratado. Tal desigualdade é extrema-

120 capitalismo ao qual o texto se refere é o capitalismo pós-industrial, transnacional e em redes que proporciona um cenário de descaracterização do paradigma clássico do Direito do Trabalho, de precarização e descoletivização das relações laborais e de esbatimento do contrato de trabalho (RODRIGUES apud FERREIRA, 2000). 
mente prejudicial às mulheres, negros/as, $\mathrm{LGBT}+{ }^{13}$ e demais sujeitos marginalizados. Dessa forma, é necessário que se aplique e analise os dois princípios da justiça (liberdade e igualdade) internamente à estrutura dos sindicatos para que represente a diversidade do tecido social. Só assim os sindicatos podem lutar por mais justiça para os trabalhadores e trabaIhadoras, enfrentando empregadores e o próprio capital.

Os sindicatos são órgãos representantes da classe trabalhadora, mas não de sua heterogeneidade. Sendo assim, necessitam ter uma estrutura interna mais igualitária, justa, inclusiva e aberta a grupos marginalizados, principalmente negros/as, mulheres e a comunidade LGBT+. Segundo Maria Antonino, "os espaços institucionais precisam refletir a sociedade, mas continuam sem conseguir esse feito" (ANTONINO, 2018).

Nesse sentido, aduz Flávia Souza Máximo Pereira que "há um conflito entre capital e trabalho, mas a desigualdade social gerada pelo capital não é simplesmente monolítica e excessiva; ela é particularmente excessiva conforme cor, sexo, nacionalidade e orientação sexual" (PEREIRA, 2017, p. 78). Por essa razão, os sindicatos precisam se reinventar internamente e externamente. Internamente, diversificando aqueles/as que ocupam os cargos de direção e externamente, voltando seu olhar para outros movimentos que extrapolam a esfera econômico-laboral, como movimentos feministas e antirracistas (FLEURY; NICOLI, 2018). As discriminações decorrentes da raça e do gênero (dentre tantas outras) apoiam e são apoiadas pelo capitalismo ${ }^{14}$, que lucra com a superexploração e precarização dessas vidas invisibilizadas (SILVA. 2008, p. 105).

De acordo com Lilian Arruda: "[...] torna-se imperiosa a "reinvenção do movimento sindical" como fator de democratização do trabalho e como reforço da "voz coletiva" (ARRUDA, 2004, p. 431). Nesse sentido, uma possível proposta de maior inclusão e representação desses sujeitos invisibilizados na estrutura dos sindicatos, para que eles se consolidem como instituições sociais justas que aplicam os dois princípios da justiça de Rawls, seria a adoção de cotas, principalmente nos cargos de direção e liderança. Principalmente, como se encontra num paradigma moderno, com cotas para mulheres, negros/as e transexuais, sendo uma medida temporária para realizar uma forma de reparação pelas constantes injustiças que esses sujeitos sofrem diariamente na sociedade e também dentro dos sindicatos.

A partir do momento em que sujeitos marginalizados ganham voz e espaço dentro dos sindicatos, eles/as passam a ter força e uma estrutura de apoio para mudar a realidade no âmbito das relações de trabalho. Segundo Lucas Petroni e Raissa Ventura, no texto "Pode a teoria normativa ter alguma contribuição na luta contra a injustiça?", a prioridade da preocupação da sociedade deveria ser em relação aqueles/as que estão pior situados e que, consequentemente, precisam de maior atenção (VENTURA; PETRONI, 2014). De acordo com Flávio Malta Fleury e Pedro Augusto Gravatá Nicoli:

130 acrônimo representa Lésbicas, Gays, Bissexuais, o termo guarda-chuva Trans, que representa pessoas transgêneras, travestis e transsexuais e o "+" representa a pluralidade e todas as demais construções que estão acrescentadas e representadas na sigla e aquelas que estão sendo incluídas.

14 Flávio Malta Fleury e Pedro Augusto Gravatá Nicoli exemplificam tal situação: "Afinal, o sistema capitalista explora, economicamente, essas modalidades de discriminação e de opressão, em eixos sobrepostos, perpetuando sua existência no mundo do trabalho e em outras dimensões da vida humana e da sociedade (COLLINS; BILGE, 2016). O capitalismo explora, economicamente, o sexismo, o racismo, a homofobia, a lesbofobia e a transfobia quando, por exemplo, emprega, preferencialmente, mulheres, pessoas negras, gays, lésbicas, travestis e transexuais em centrais de teleatividades, mais usualmente conhecidas como call centers, onde a existência dessas pessoas é invisibilizada e ocultada de 'uma sociedade de consumo que privilegia certos padrões estéticos' (VENCO, 2009, p. 170)" (FLEURY; NICOLI, 2018, p. 13). 
A emancipação individual e coletiva de trabalhadoras e trabalhadores deve perpassar, necessariamente, o enfrentamento a todas as formas de discriminação e de opressão das quais são vítimas dentro do ambiente de trabaIho, quando conseguem acessá-lo, e fora dele (FLEURY; NICOLI, 2018, p. 13).

Tem-se o desafio de compreender as conexões complexas entre gênero, classe e raça, componentes fundamentais das desigualdades, e o que percebe-se é que os sindicatos são reproduções dessas desigualdades. Tal comportamento excludente dos sindicatos aprofunda sua crise, vez que mulheres, negros/as, LGBT+ entre outros sujeitos constantemente marginalizados param de se identificar com a instituição, que não os representa. Assim, o sindicato perde cada vez mais adeptos e se enfraquece. Nas palavras de Adriana L. Saraiva Lamounier Rodrigues:

De modo geral, a crise da representatividade significa a perda da capacidade de o sindicato unir os comportamentos dos trabalhadores, e de representar a vontade da coletividade obreira. Se todos os trabalhadores perdem a identificação com sua própria entidade, a crise transforma-se em declínio (RODRIGUES, 2018, p. 91).

Portanto, para que o movimento sindical recupere o fôlego e a força, precisa construir sindicatos mais justos e democráticos e, para issoserá necessária uma atuação afirmativa e reparadora, para incluir sujeitos socialmente excluídos em sua estrutura interna.

A igualdade na presença e atuação das mulheres, negros(as), LGBT+ nos sindicatos é um projeto que beneficiará a sociedade como um todo (ANTONINO, 2018), transformando o ciclo vicioso, abordado anteriormente, em um ciclo virtuoso de inclusão e participação plural da heterogênea classe trabalhadora, que procura acabar com as desigualdades, respeitando as diferenças, dentro das instituições sociais e da sociedade.

Portanto uma atuação justa no interior dos sindicatos pode ter uma implicação direta na diminuição das injustiças no mercado de trabalho. Se a diversidade de sujeitos trabalhadores é contemplada na dinâmica sindical e do mercado de trabalho, com oportunidades, ocupação de cargos de destaque, usufruindo de uma maior visibilidade, isso ecoará efeitos em várias esferas da sociedade, como índices de desemprego, escolaridade, violência, miséria, maior poder econômico e aquisitivo da população, entre outros.

\section{CONSIDERAÇÓES FINAIS}

Frente a isso, sem a pretensão de finalizar a discussão, tem-se que os sindicatos, que tem assento constitucional, são entes coletivos que representam trabalhadoras e trabalhadores, possuindo estatuto próprio, cargos, direitos e deveres atribuídos aos seus membros e, por isso, configuram-se como instituições sociais da visão de John Rawls. Segundo Rawls, o que contribui para que uma sociedade seja justa, é o bom funcionamento das suas instituições sociais.

Dessa forma, o cenário atual de organização e atuação interna da grande maioria dos sindicatos demonstra que eles são instituições sociais injustas, patriarcais e hierarquizadas, que raramente representam a heterogeneidade da classe trabalhadora, vez que são forma- 
dos, em sua grande maioria, por homens brancos e cis. Dessa forma, os sindicatos acabam por reproduzir a desigualdade estrutural que há na sociedade em sua organização interna, excluindo sujeitos marginalizados, como mulheres, negros(as) e transexuais.

Igualmente, a aplicação da "Teoria da Justiça" e dos princípios da justiça de John Rawls, especialmente do segundo (igualdade), na organização sindical, apesar de ser uma tarefa extremamente difícil, pode resultar em uma estrutura sindical mais justa e inclusiva, que acolha e dê visibilidade àqueles/as trabalhadores/as que são marginalizados/as pela sociedade e excluídos do mercado de trabalho.

Nesse sentido, tratando-se no sentido da igualdade material, a aplicação de cotas de gênero, identidade de gênero e raça na estrutura dos sindicatos, principalmente, em relação aos cargos de maior protagonismo, pode funcionar como uma forma de dar visibilidade a essas pautas e setores marginalizados da sociedade na história da modernidade e, também, uma reparação histórica às desigualdades injustas e maléficas sofridas pelos mesmos.

Assim, entende-se que uma atuação justa e equilibrada no interior dos sindicatos pode impactar diretamente na dinâmica do mercado de trabalho e no tratamento das relações trabalhistas de todos(as) que exercem a atividade laborativa, em especial, daqueles mais marginalizados e invisibilizados por uma sociedade patriarcal, preconceituosa e racista.

Diante disso, a partir do momento que esses/as sujeitos ganharem protagonismo dentro dessas instituições sociais e apoio da numerosa e heterogênea classe trabalhadora, o mercado, sendo entendido como uma instituição heterogênea, provavelmente, terá que ceder às suas pressões e reivindicações diretas por meio da luta constante e coletiva, pois a classe trabalhadora articulada e com representação plural é mais numerosa, em volume, força de consumo e reinvindicação, que qualquer outra e, quando unida, atenta as demandas sociais e solidificada, tem muito mais força do que imagina, como, por exemplo, ter espaços para realizar mais conquistas de direitos, expansão dos sujeitos protegidos dentro da relação de emprego.

\section{REFERÊNCIAS}

ANTONINO, Maria. Mulher, política e representatividade: meu voto será feminista e o seu? QG Feminista, [S. I.], 3 out. 2018. Disponível em: https://medium.com/qg-feminista/mulher-política-e-representatividade-3904e5db6f5d. Acesso em: 4 jul. 2020.

BABOIN, José Carlos de Carvalho. O tratamento jurisprudencial da greve política no Brasil. Dissertação de Mestrado. Faculdade de Direito da Universidade de São Paulo - USP. São Paulo, 2013.

BALLESTRIN, Luciana. América Latina e o giro decolonial. Rev. Bras. Ciênc. Polít. [online]. 2013, n. 11, pp. 89-117. ISSN 0103-3352. Disponível em: http://dx.doi.org/10.1590/S0103-33522013000200004. Acesso em: 4 jun. 2020.

CONFEDERAÇÃO Nacional dos Trabalhadores em Transportes e Logística. Oficina "Todo poder às mulheres nos sindicatos" debate participação feminina no movimento sindical. Publicado em 22 jan. 2016. Disponível em: https://cnttl.org.br/noticia/5648/oficina-todo-poder-as-mulheres-nos-sindicatos-debate-participacao-feminina-no-movimento-sindical. Acesso em: 02 jun. 2020.

EISENSTEIN, Zillah. An Alert: Capital is Intersectional; Radicalizing Piketty's Inequality. The feminist Wire, Phoenix, 2014. 
FORST, Rainer. Justificação e Crítica. Perspectivas de uma teoria crítica da política. Tradução Denilson Luis Werle. São Paulo: Editora Unesp, 2018.

GUSTIN, Miracy Barbosa de Sousa; DIAS, Maria Tereza Fonseca Dias. (Re)Pensando a Pesquisa Jurídica: Teoria e Prática. Belo Horizonte, Del Rey Editora, 2013.

MARX, Karl. O Capital: Crítica da economia política. Livro I: O processo de produção do capital. Trad. Rubens Enderle. São Paulo: Boitempo, 2014.

PIMENTA, Sara Deolinda Cardoso. Participação, poder e democracia - mulheres trabalhadoras no sindicalismo rural. Seminário Internacional Fazendo Gênero 10 (Anais Eletrônicos). Florianópolis: 2012.

RAWLS, John. Uma teoria da justiça. Trad. Jussara Simões. $3^{a}$ ed. São Paulo: Martins Fontes, 2008.

RODRIGUES, Adriana Letícia Saraiva Lamounier. Redes Sindicais Internacionais: Uma contribuição ao fortalecimento do Direito do Trabalho na Itália e no Brasil. Bauru: Praxis, Canal 6, 2018.

VENTURA, R. W.; PETRONI, L. Pode a teoria normativa ter alguma contribuição na luta contra a injustiça? Conexão Política. [s.I.] Universidade Federal do Piauí, 2014. v. 3. Disponível em: http://www.ojs.ufpi.br/index.php/conexaopolitica/article/view/3550/2038. Acessos em 02 jun. 2020.

WERLE, Denilson Luis. Liberdades Básicas, Justificação Públicas e Poder Político em John Rawls. Org: Denis Coitinho Silveira. Ed: Luís Rubira e Robinson dos Santos. Universidade Federal de Santa Catarina. DISSERTATIO Revista de Filosofia, v. 34, ano 2011.

Recebido/Received: 23.03.2020.

Aprovado/Approved: 26.09.2020. 